\title{
High mobility group (HMG) non-histone chromosomal proteins HMG1 and HMG2 are significant target antigens of perinuclear anti-neutrophil cytoplasmic antibodies in autoimmune hepatitis
}

J Sobajima, S Ozaki, H Uesugi, F Osakada, M Inoue, Y Fukuda, H Shirakawa, M Yoshida, A Rokuhara, H Imai, K Kiyosawa, K Nakao

Department of Medicine and Clinical Science, Kyoto

University Graduate

School of Medicine, 54

Shogoin-Kawahara-cho,

Sakyo-ku, Kyoto

606-8507, Japan

J Sobajima

S Ozaki

H Uesugi

$M$ Inoue

Y Fukuda

K Nakao

Kaneka Corporation, 1-8, Miyamae-machi, Takasago-cho,

Takasago-shi, Hyogo 676-0027, Japan

F Osakada

Department of Biological Science and Technology, Science University of Tokyo, Yamazaki, Noda, Chiba 278-0022, Japan H Shirakawa M Yoshida

Second Department of Internal Medicine, Shinshu University

School of Medicine, 3-1-1, Asahi,

Matsumoto, Nagano

390-0802, Japan

A Rokuhara

H Imai

K Kiyosawa

Correspondence to: Dr S Ozaki, Department of Medicine and Clinical Science, Kyoto University Graduate School of

Medicine, 54

Shogoin-Kawahara-cho,

Sakyo-ku, Kyoto 606-8507, Japan.

Accepted for publication 5 January 1999
Abstract

Background-High mobility group (HMG) non-histone chromosomal proteins HMG1 and HMG2 have been identified as novel antigens of perinuclear antineutrophil cytoplasmic antibodies (pANCAs), and the existence of anti-HMG1 and anti-HMG2 antibodies in a population of patients with ulcerative colitis has been reported.

Aims-To investigate whether HMG1 and HMG2 are target antigens for p-ANCAs in autoimmune hepatitis (AIH).

Patients-Serum samples from 28 patients with AIH, 44 patients with primary biliary cirrhosis (PBC), 27 patients with chronic hepatitis $C$, and 23 patients with chronic hepatitis B were tested.

Methods-ANCAs were detected by routine indirect immunofluorescence (IIF). Anti-HMG1 and anti-HMG2 antibodies were assayed by enzyme linked immunosorbent assay.

Results-p-ANCAs were detected in $89 \%$ (25/28) of patients with AIH, 36\% (16/44) of patients with PBC, 11\% (3/27) of patients with chronic hepatitis $C$, and $13 \%(3 / 23)$ of patients with chronic hepatitis B. AntiHMG1 and/or anti-HMG2 antibodies were detected in $89 \%(25 / 28)$ of patients with AIH, 70\% (31/44) with PBC, 26\% (7/27) with chronic hepatitis $\mathrm{C}$, and 9\% (2/23) with chronic hepatitis B. In AIH, antiHMG1 and/or anti-HMG2 antibodies were detected in $96 \%(24 / 25)$ of p-ANCA positive patients. The p-ANCA staining pattern detected by IIF using sera from patients with AIH disappeared or decreased in titre after preincubation with a mixture of HMG1/HMG2. The presence and titres of those antibodies in AIH correlated significantly with those of p-ANCA, but not with those of antinuclear antibody or anti-smooth muscle antibody.

Conclusions-HMG1 and HMG2 are significant target antigens of p-ANCA in AIH.

(Gut 1999;44:867-873)

Keywords: perinuclear anti-neutrophil cytoplasmic antibodies; chromosomal proteins; high mobility group 1 and 2; autoimmune; hepatitis
Anti-neutrophil cytoplasmic antibodies (ANCAs) are directed against the cytoplasmic components of neutrophils. They can be divided into two major subtypes by indirect immunofluorescence (IIF) using ethanol fixed neutrophils as substrates: those showing a cytoplasmic pattern (c-ANCAs) and those showing a perinuclear pattern ( $\mathrm{p}$-ANCAs). Most c-ANCAs are specific for proteinase $3,{ }^{1-3}$ and a substantial proportion of p-ANCAs are directed against myeloperoxidase. ${ }^{4}$ The strong association of ANCAs with systemic vasculitis has been established: proteinase 3-ANCAs are more commonly found in patients with Wegener's granulomatosis ${ }^{1-3}$ and myeloperoxidase -ANCAs are more commonly found in patients with vasculitis limited to the kidney. ${ }^{4}$

p-ANCAs have been associated not only with systemic vasculitis but also with nonvasculitic diseases, such as inflammatory bowel disease $^{5-8}$ and chronic liver diseases. ${ }^{9-13}$ In autoimmune liver diseases, particularly autoimmune hepatitis (AIH) and primary sclerosing cholangitis (PSC), p-ANCAs are commonly detected. These p-ANCAs do not react with myeloperoxidase, and it has been speculated that their target antigens are different from the granule proteins of neutrophils reported previously. ${ }^{9-11} 13$ Recent studies have reported that actin is one of the target antigens of ANCAs in $\mathrm{AIH}^{14}$ and that catalase and $\alpha$-enolase are those in PSC. ${ }^{15}$ However, the main target antigens remain unclear.

Recently, we identified high mobility group (HMG) non-histone chromosomal proteins HMG1 and HMG2 as novel antigens of p-ANCAs, and reported the existence of anti-HMG1/HMG2 antibodies in a population of patients with ulcerative colitis ${ }^{16-18}$ and systemic rheumatic diseases. ${ }^{19}$ HMG1 and HMG2, which are distributed not only in the nuclei but also in the cytoplasm of eukaryotic

Abbreviations used in this paper: ANCA, anti-neutrophil cytoplasmic antibody; IIF, indirect immunofluorescence; c-ANCA, cytoplasmic anti-neutrophil cytoplasmic antibody; p-ANCA, perinuclear anti-neutrophil cytoplasmic antibody; $\mathrm{AIH}$, autoimmune hepatitis; PSC, primary sclerosing cholangitis; HMG, high mobility group; ELISA, enzyme linked immunosorbent assay; PBC, primary biliary cirrhosis; ANA, anti-nuclear antibody; SMA, anti-smooth muscle antibody; AMA, anti-mitochondrial antibody. 
cells, are known to act as transcriptional factors. ${ }^{20-22}$ In spite of their ubiquitous distribution, we found that some monoclonal antiHMG1/HMG2 antibodies showed a perinuclear staining pattern of ethanol fixed neutrophils on IIF, and that these antibodies did not stain lymphocytes or HEp-2 cells. $^{23}$ These results indicate that antibodies against HMG1 and HMG2 fulfil the criteria of p-ANCAs ${ }^{4}$ Interestingly, in western blotting using neutrophils, these antibodies exhibited different bands from those using lymphocytes or HEp-2 cells (unpublished observation), suggesting that HMG1 and HMG2 in neutrophils may be distinct from those in lymphocytes or HEp- 2 cells.

The amino acid sequences of HMG1/ HMG2 are highly conserved among speciesfor instance, there are only two amino acid differences between human and porcine HMG1/HMG 2. ${ }^{2024}$ Because of this high degree of conservation in primary sequences, anti-human HMG1/HMG2 sera cross reacted with porcine HMG1 and HMG2 ${ }^{17}$ Therefore we established an enzyme linked immunosorbent assay (ELISA) system using porcine HMG1/HMG2 as antigens instead of human proteins.

In this study, we studied the prevalence of anti-HMG1/HMG2 antibodies in chronic liver diseases - that is, autoimmune hepatitis (AIH), primary biliary cirrhosis (PBC), and chronic hepatitis $C$ and $B$, using the ELISA system and analysed the relations between anti-HMG1/ HMG 2 antibodies and p-ANCAs in these diseases. Furthermore, we analysed the relations between anti-HMG1/HMG2 antibodies and antibodies to cathepsin $G$ and lactoferrin, which are reported to be target antigens of p-ANCAs, ${ }^{28}{ }^{29}$ and other autoantibodies such as anti-nuclear antibody (ANA), anti-smooth muscle antibody (SMA), and antimitochondrial antibody (AMA), which are useful seromarkers for AIH or PBC.

\section{Patients and methods}

PATIENTS

Sera from 28 patients with $\mathrm{AIH}$ and 44 patients with PBC were studied (table 1). The diagnoses of AIH and PBC were made on the basis of clinical, serological, and histological criteria. ${ }^{30}$ All 28 patients with AIH lacked other causes of chronic liver disease such as metabolic, drug related, and viral including hepatitis A, hepatitis B, and hepatitis C virus. All patients had persistent elevation of serum aminotransferases, IgG (>2500 mg/dl), and non-organ-specific autoantibodies. In all cases, liver biopsy specimens showed moderate or severe piecemeal necrosis and inflammatory mononuclear cell infiltration into the portal tract. Seven patients had other immunological diseases: two had Sjögren's syndrome, one had Sjögren's syndrome and chronic thyroiditis, one had chronic thyroiditis, one had rheumatoid arthritis, one had rheumatoid arthritis and systemic sclerosis, and one had systemic sclerosis. The activity index was determined according to the definition of the international autoimmune hepatitis group. ${ }^{31}$ Five patients had been treated with prednisolone (5-40 $\mathrm{mg}$ /day) at the time of blood sampling.

All 44 patients with PBC had cholestatic liver disease. Thirty one patients showed chronic non-suppurative destructive cholangitis on liver biopsy specimens. The remaining 13 were positive for serum AMA and/or antipyruvate dehydrogenase antibody and showed liver histology compatible with PBC. Twelve patients had other immunological diseases: five had Sjögren's syndrome, one had Sjögren's syndrome and rheumatoid arthritis, two had Sjögren's syndrome and systemic sclerosis, one had systemic sclerosis, two had systemic sclerosis and chronic thyroiditis, and one had chronic thyroiditis. One patient had been treated with prednisolone $(10 \mathrm{mg} /$ day $)$ at the time of blood sampling.

As disease controls, we tested sera from patients with chronic viral hepatitis: 27 patients with chronic hepatitis $\mathrm{C}$ and 23 with chronic hepatitis B diagnosed by liver biopsy and serology (second generation assays). Twenty four age matched healthy blood donors served as normal controls. Informed consent was obtained from each subject. The sample sera were stored at $-20^{\circ} \mathrm{C}$.

\section{MATERIALS}

Porcine HMG1 and HMG2 were purified from pig thymus as described elsewhere. ${ }^{32}$ Human cathepsin G (ICN Biomedicals, Cleveland, Ohio, USA) and human lactoferrin (Sigma, St Louis, Missouri, USA) were purchased. Their

Table 1 Patients and normal controls

\begin{tabular}{|c|c|c|c|c|c|}
\hline \multirow[b]{2}{*}{ Characteristics } & \multicolumn{5}{|l|}{ Diagnosis } \\
\hline & $A I H$ & $P B C$ & $\begin{array}{l}\text { Viral } \\
\text { hepatitis } C\end{array}$ & $\begin{array}{l}\text { Viral } \\
\text { hepatitis B }\end{array}$ & $\begin{array}{l}\text { Normal } \\
\text { controls }\end{array}$ \\
\hline No of patients and controls & 28 & 44 & 27 & 23 & 24 \\
\hline $\operatorname{Sex}(M / F)$ & $6 / 22$ & $4 / 40$ & $15 / 12$ & $15 / 8$ & $8 / 16$ \\
\hline Median age (years) ${ }^{\star}$ & $52(24-80)$ & $60(36-71)$ & $53(30-62)$ & $30(20-56)$ & $51(34-77)$ \\
\hline Other immunological diseasest & $7(25)$ & $12(27)$ & $1(4)$ & $0(0)$ & $0(0)$ \\
\hline (concomitant presence of UCt) & $0(0)$ & $0(0)$ & $0(0)$ & $0(0)$ & $0(0)$ \\
\hline Positive ANA $(\geqslant 1: 40) \dagger$ & $25(89)$ & $29(66)$ & $2(7)$ & $1(4)$ & $0(0)$ \\
\hline Positive SMA $(\geqslant 1: 40)+$ & $16(57)$ & $1(2)$ & $6(22)$ & $0(0)$ & $0(0)$ \\
\hline Positive AMA $(\geqslant 1: 40) \dagger$ & $3(11)$ & $33(75)$ & $0(0)$ & $0(0)$ & $0(0)$ \\
\hline Presence of cirrhosist & $3(11)$ & $11(25)$ & $4(15)$ & $3(13)$ & $0(0)$ \\
\hline Use of prednisolone at the time of samplingt & $5(18)$ & $1(2)$ & $0(0)$ & $0(0)$ & $0(0)$ \\
\hline
\end{tabular}

${ }^{\star}$ Data in parentheses represent ranges.

tData expressed as number of patients (percentage of whole)

$\mathrm{AIH}$, autoimmune hepatitis; PBC, primary biliary cirrhosis; UC, ulcerative colitis; ANA, anti-nuclear antibody; SMA, anti-smooth muscle antibody; AMA, anti-mitochondrial antibody. 
purity was confirmed by sodium dodecyl sulphate/polyacrylamide gel electrophoresis. Neutrophils were isolated from peripheral blood obtained from normal human volunteers by Ficoll density gradient centrifugation. Affinity purified anti-HMG1/HMG2 antibody was obtained by applying the serum from a p-ANCA positive patient to an HMG1/HMG2 affinity column.

IIF ASSAY

ANCA activity was determined by IIF assay as described by Wiik. ${ }^{33}$ Briefly, ethanol fixed cytospin preparations of human neutrophils were incubated with serum at room temperature for 20 minutes at an initial dilution of 1:10 or $1: 125$ in phosphate buffered saline and in twofold dilutions thereof. As the secondary antibody, fluorescein isothiocyanate conjugated $\mathrm{F}\left(\mathrm{ab} \mathrm{b}^{\prime}\right)_{2}$ rabbit anti-human IgG (Serotec, Oxford, UK) was used. The slides were evaluated by fluorescence microscopy. ANCA titres were determined as the reciprocals of final dilutions to give positive staining. As controls, p-ANCA and c-ANCA positive sera were purchased from Binding Site (Birmingham, UK). Samples positive for perinuclear or nuclear
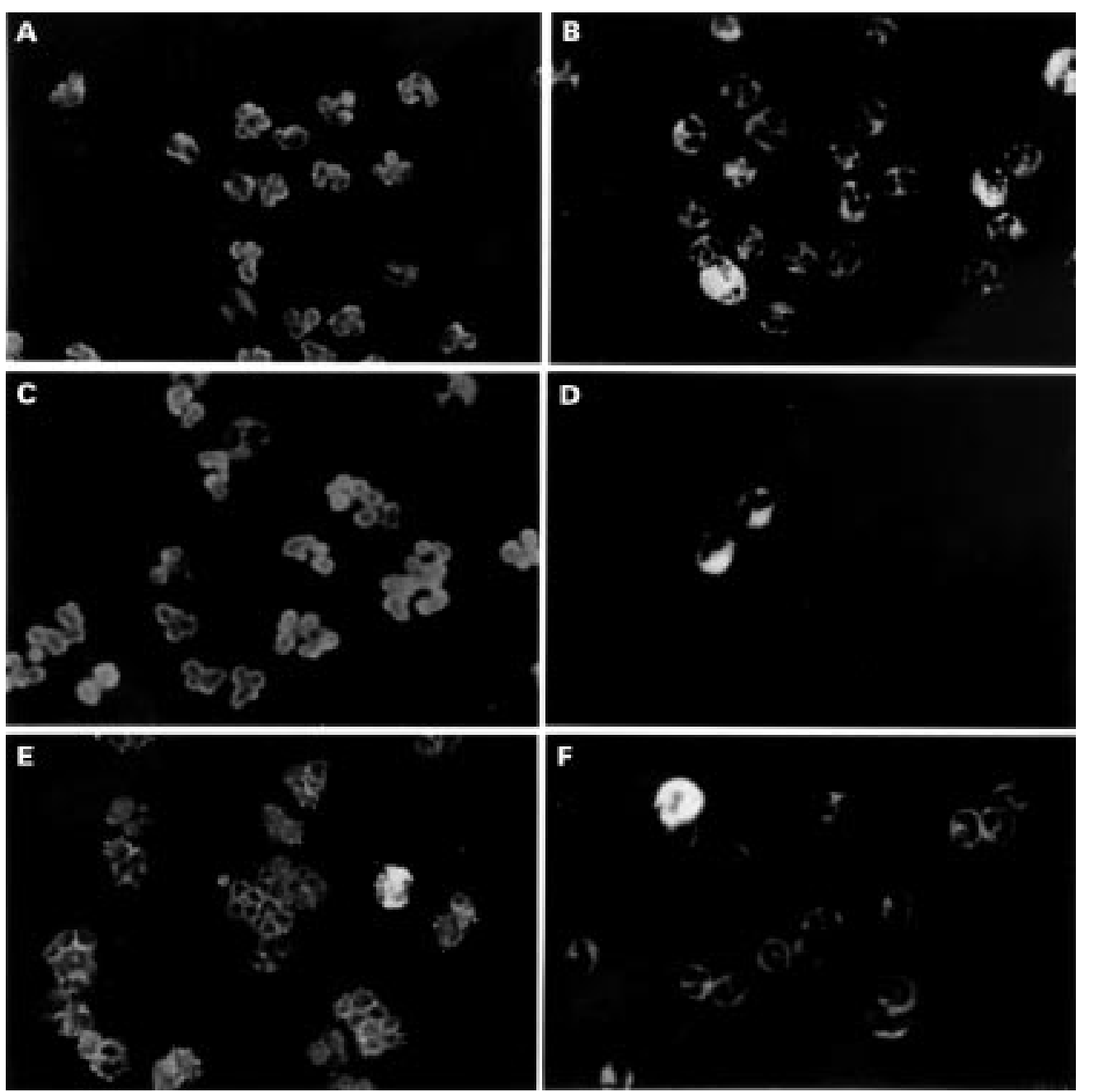

Figure 1 Perinuclear anti-neutrophil cytoplasmic antibody activities on indirect immunofluorescence. Sera from patient with autoimmune hepatitis $(A, B)$ and primary biliary cirrhosis $(C, D)$, and an affinity purified anti-HMG1/HMG2 antibody $(E, F)$ showing perinuclear staining on ethanol fixed neutrophils $(A, C, E)$ and cytoplasmic or negative staining on formalin fixed neutrophils $(B, D, F)$.

staining were subjected to formalin fixation, instead of ethanol fixation, to distinguish ANCAs from antibodies to neutrophil nuclei. p-ANCAs were regarded as positive when they showed perinuclear or nuclear staining on ethanol fixed neutrophils and cytoplasmic or negative staining on formalin fixed

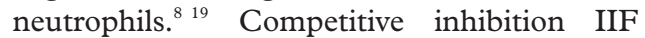
using an HMG1/HMG2 mixture was performed to determine the specificity of reactivity to HMG1/HMG2. Double positive sera for p-ANCA and anti-HMG1/HMG2 antibodies were diluted at optimal dilutions that were 8or 16-fold more concentrated than their final dilutions to give p-ANCA positive staining. These sera were preincubated with equal volumes of HMG1/HMG2 mixture (100 $\mu \mathrm{g} / \mathrm{ml}$ ) or phosphate buffered saline for 30 minutes at room temperature, and were used for subsequent IIF assays in parallel to AMA the ANCA titres. ANA, SMA, and kits: fluoro HEPANA test for ANA, and fluoro AID-1 test for SMA and AMA (MBL, Nagoya, Japan). Sera were considered positive for ANA, SMA, and AMA at a dilution of $\geqslant 1: 40$. 
Table 2 Frequencies of antibodies to HMG1, HMG2, cathepsin G, and lactoferrin

\begin{tabular}{|c|c|c|c|c|c|c|c|}
\hline \multirow[b]{2}{*}{ Disease $(n)$} & \multirow[b]{2}{*}{$p-A N C A(n)$} & \multicolumn{6}{|c|}{ Number of sera positive for antibodies to: } \\
\hline & & $H M G 1$ & $H M G 2$ & $\begin{array}{l}H M G 1 \\
\text { or } 2^{\star}\end{array}$ & $\begin{array}{l}H M G 1 \\
\text { and } 2 f\end{array}$ & Cathepsin G & Lactoferrin \\
\hline \multirow[t]{2}{*}{$\mathrm{AIH}(28)$} & Positive (25) & 22 & $23 \ddagger$ & $24 \rrbracket$ & 21 & 23 & 5 \\
\hline & Negative (3) & 1 & 1 & 1 & 1 & 2 & 0 \\
\hline \multirow{2}{*}{ PBC (44) } & Positive (16) & 12 & 12 & 13 & 11 & 15 & 1 \\
\hline & Negative (28) & 14 & 16 & 18 & 12 & 23 & 4 \\
\hline \multirow[t]{2}{*}{ Chronic hepatitis C (27) } & Positive (3) & 2 & 2 & 2 & 2 & 2 & 0 \\
\hline & Negative (24) & 5 & 4 & 5 & 4 & 8 & 2 \\
\hline \multirow[t]{2}{*}{ Chronic hepatitis B (23) } & Positive (3) & 0 & 1 & 1 & 0 & 2 & 1 \\
\hline & Negative (20) & 0 & 1 & 1 & 0 & 2 & 6 \\
\hline
\end{tabular}

^Positive for antibodies to either HMG1 or HMG2.

†Positive for antibodies to both HMG1 and HMG2.

p-ANCA, perinuclear anti-neutrophil cytoplasmic antibodies; AIH, autoimmune hepatitis; PBC, primary biliary cirrhosis.

$\neq \mathrm{p}=0.045$ (Fisher's exact test).

$\mathrm{Sp}=0.023$ (Fisher's exact test).

ELISA

Antibodies to HMG1, HMG2, cathepsin G, and lactoferrin were assayed by ELISA as described elsewhere. ${ }^{18}$ Briefly, $50 \mu \mathrm{l}$ of $5 \mu \mathrm{g} / \mathrm{ml}$ HMG1 and HMG2 in phosphate buffered saline, $\mathrm{pH}$ 7.4, cathepsin $\mathrm{G}$ in $500 \mathrm{mM}$ sodium acetate with $150 \mathrm{mM} \mathrm{NaCl}, \mathrm{pH}$ 5.5, and lactoferrin in bicarbonate buffer, $\mathrm{pH}$ 9.6, were respectively put on microtitre plates (Immunoplate maxisorp; Nunc, Roskilde, Denmark). Serum samples were diluted 1:40 in phosphate buffered saline containing $5 \%$ bovine serum albumin, and the secondary antibody used was alkaline phosphatase conjugated $\mathrm{F}(\mathrm{ab})_{2}$ goat anti-human IgG (Immunotech, Marseille, France). Antibody titres were expressed as $\mathrm{U} / \mathrm{ml}$ by reference to the dilution curves for positive control sera, the titres of which were arbitrarily set at $100 \mathrm{U} / \mathrm{ml}$. A level $>3$ SD above the mean for normal sera was regarded as positive. Competitive inhibition ELISA using HMG1, HMG2, cathepsin G, and lactoferrin was performed to determine the specificity of reactivity to the respective proteins. The corre-

A

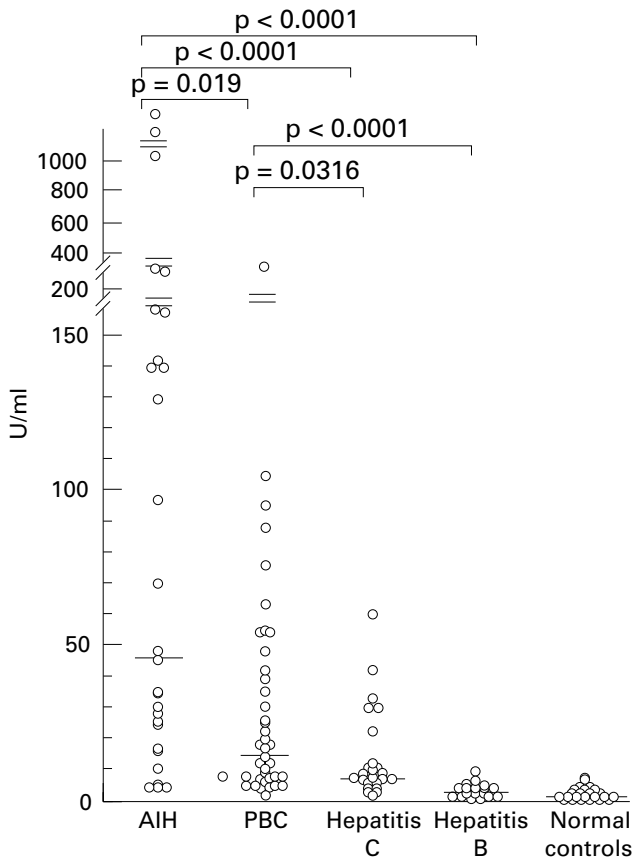

sponding antibody positive sera at optimal dilutions were preincubated with equal volumes of HMG1, HMG2, cathepsin G, and lactoferrin of various concentrations for 30 minutes at room temperature. Ovalbumin was used as a control.

\section{STATISTICAL ANALYSIS}

The results were analysed by the MannWhitney U test, Wilcoxon signed rank test, Fisher's exact test, and the Spearman rank correlation test. In these analyses, values of $p<0.05$ were considered statistically significant.

\section{Results}

DETECTION OF ANCAS BY IIF

ANCAs were tested by IIF in serum from patients with chronic liver diseases. p-ANCAs were detected in $25(89 \%)$ of 28 sera from patients with $\mathrm{AIH}, 16(36 \%)$ of 44 from patients with PBC, three (11\%) of 27 from patients with chronic hepatitis $\mathrm{C}$, and three (13\%) of 23 from patients with chronic hepatitis $\mathrm{B}$. Among the sera with positive perinuclear

B

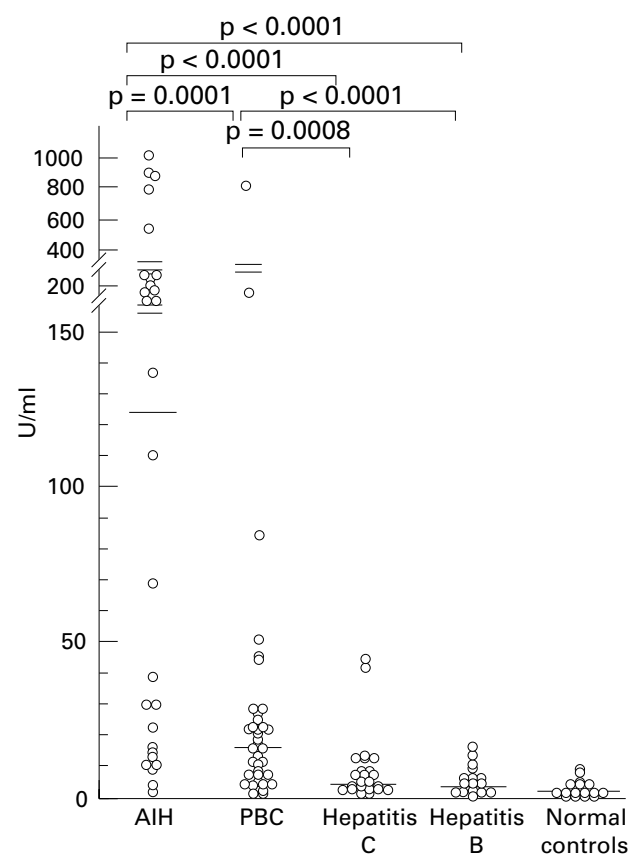

Figure 2 Titres of antibodies to HMG1 (A) and HMG2 (B) determined by ELISA. AIH, autoimmune hepatitis; PBC, primary biliary cirrhosis. The solid lines represent median values of antibody titres. $p$ values by Mann-Whitney $U$ test. 


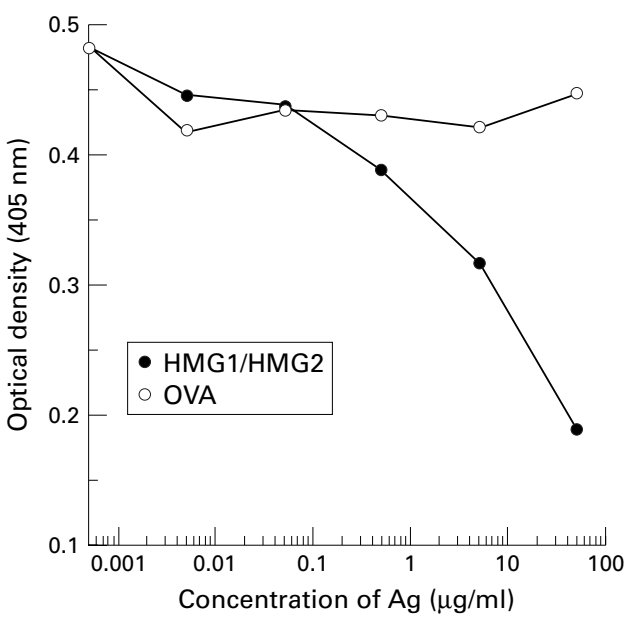

Figure 3 Competitive inhibition ELISA.

Anti-HMG1/HMG2 antibody positive serum from a patient with autoimmune hepatitis was preincubated with a mixture of HMG1 and HMG2 or ovalbumin (OVA) at the concentrations indicated. In a subsequent HMG1/HMG2 ELISA, the reactivity decreased in a dose dependent manner when preincubated with HMG1/HMG2, but not with ovalbumin.

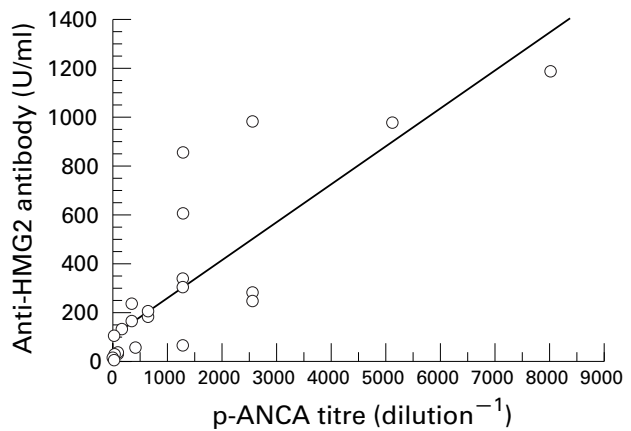

Figure 4 Correlation between the titres of anti-HMG2 antibody and perinuclear anti-neutrophil cytoplasmic antibodies in autoimmune hepatitis. A positive correlation was found between the two parameters $(r=0.8264$, $p<0.0001$, Spearman rank correlation test).


Figure 5 Disappearance of perinuclear anti-neutrophil cytoplasmic antibody ( $p$ - $A N C A)$ staining after preincubation with specific antigens. Serum from a patient with autoimmune hepatitis with a $p$-ANCA titre of 1280 was diluted at $1: 160$ and preincubated with an equal volume of $100 \mu \mathrm{g} / \mathrm{ml}$ of a mixture of HMG1 and HMG2 (B) or phosphate buffered saline $(A)$. Subsequent IIF was performed by each solution, and photographs were taken at the same exposure. No fluorescence was visible in (B), where the only bright cell is an eosinophil with spontaneous fluorescence. staining on ethanol fixed neutrophils, cytoplasmic fluorescent patterns on formalin fixed neutrophils were detected in $24(96 \%)$ of 25 sera from patients with AIH, $10(62 \%)$ of 16 sera from patients with PBC, two $(67 \%)$ of three sera from patients with chronic hepatitis C, and two $(67 \%)$ of three sera from patients with chronic hepatitis $\mathrm{B}$. The remaining sera showed negative staining. We considered these two patterns as positive for p-ANCAs as described elsewhere. ${ }^{819}$ Median titres of the p-ANCA positive sera were 640 (range 108000) for AIH and 20 (range 10-640) for PBC. Figure 1 shows some representative results. On the other hand, c-ANCAs were only detected in $9 \%$ of PBC sera. Neither p-ANCAs nor c-ANCAs were detected in normal control sera.

ANTIBODIES TO HMG1, HMG2, CATHEPSIN G, AND LACTOFERRIN ASSAYED BY ELISA

All sera from patients with AIH, PBC, chronic hepatitis $\mathrm{C}$, and chronic hepatitis B were tested for reactivity to HMG1, HMG2, cathepsin G, and lactoferrin by ELISA. Table 2 summarises the frequencies of those antibodies. Antibodies to HMG1, HMG2, and cathepsin G were more commonly detected in patients with AIH and PBC than in patients with chronic hepatitis C and $\mathrm{B}$. The titres of antibodies to HMG1 and HMG2 in AIH were significantly higher than in PBC, chronic hepatitis C and B (fig 2). The titres of antibodies to HMG1 and HMG2 in PBC were significantly higher than in chronic hepatitis $\mathrm{C}$ and $\mathrm{B}$. These positive sera for antibodies to HMG1, HMG2, cathepsin G, and lactoferrin seemed to be specific, as the preincubation of the sera with the corresponding antigens abrogated reactivity in the subsequent ELISA. Figure 3 shows representative results.

RELATIONS BETWEEN p-ANCAS AND ANTI-HMG1 AND/OR ANTI-HMG2 ANTIBODIES

In $\mathrm{AIH}$, the presence of p-ANCAs correlated significantly with the presence of anti-HMG1 and/or anti-HMG2 antibodies, but not with the presence of anti-cathepsin $G$ and antilactoferrin antibodies (table 2). The titres of p-ANCAs correlated significantly with the titres of anti-HMG2 antibody (fig 4) and weakly with the titres of anti-HMG1 antibody (Spearman rank correlation, $r=0.3111, \mathrm{p}=$ 0.0004). From p-ANCA and anti-HMG1/ HMG2 antibody positive sera of patients with $\mathrm{AIH}$, we selected four specimens with negative or low titres of anti-cathepsin G or antilactoferrin antibodies for competitive inhibition IIF. The titres of p-ANCAs decreased after preincubation with a mixture of HMG1/ HMG2 (one serum from 5120 to $<320$, one serum from 1280 to $<320$, and two from 320 to $80)$. Figure 5 shows representative results.

In PBC, the presence of p-ANCAs did not correlate with the presence of anti-HMG1 and/or anti-HMG2 antibodies (table 2), although titres of p-ANCAs correlated weakly with titres of anti-HMG2 antibody (Spearman rank correlation, $\mathrm{p}=0.042$ ). 
Table 3 Relations between antibodies to HMG1/HMG2 and $A N A, S M A$ and $A M A$

\begin{tabular}{llll}
\hline & & \multicolumn{2}{c}{$\begin{array}{l}\text { Number of sera positive } \\
\text { for antibodies to HMG1 } \\
\text { or HMG2 }\end{array}$} \\
\cline { 3 - 4 } Disease (n) & Autoantibodies (n) & Positive & Negative \\
\hline AIH (28) & ANA+ (25) & 23 & 2 \\
& ANA- (3) & 2 & 1 \\
& SMA+ (16) & 15 & 1 \\
& SMA- (12) & 10 & 2 \\
PBC (44) & ANA+ (29) & $24^{\star}$ & 5 \\
& ANA- (15) & 7 & 8 \\
& AMA+ (33) & 25 & 8 \\
& AMA- (11) & 6 & 5 \\
\hline
\end{tabular}

AIH, autoimmune hepatitis; PBC, primary biliary cirrhosis; ANA, anti-nuclear antibody; SMA, anti-smooth muscle antibody; AMA, anti-mitochondrial antibody. ${ }^{\star} \mathrm{p}=0.017$ (Fisher's exact test).

RELATIONS BETWEEN ANTI-HMG1 AND/OR ANTI-HMG2 ANTIBODIES AND ANA, SMA, AND AMA Of 28 patients with AIH, ANA and SMA were detected in $25(89 \%)$ and $16(57 \%)$ respectively (table 1). Of 44 patients with PBC, ANA and AMA were detected in $29(66 \%)$ and 33 (75\%) respectively. The frequencies of SMA and AMA in our study were lower than in previous studies, ${ }^{101314}$ presumably because we considered ANA, SMA, and AMA as positive at a dilution of $\geqslant 1: 40$, instead of $\geqslant 1: 20$. In $\mathrm{AIH}$, the presence of anti-HMG1 and/or antiHMG2 antibodies did not correlate with the presence or absence of ANA or SMA (table 3). In PBC, however, anti-HMG1 and/or antiHMG2 antibodies significantly correlated with the presence of ANA, but did not correlate with the presence of AMA.

ASSOCIATION OF ANTI-HMG1 OR ANTI-HMG2 ANTIBODIES AND CLINICAL FEATURES

We investigated the association between antiHMG1 or anti-HMG2 antibodies with clinical features in patients with $\mathrm{AIH}$ and PBC. The

Table 4 Association of anti-HMG1 or anti-HMG2 antibodies and clinical features in patients with autoimmune hepatitis

\begin{tabular}{|c|c|c|c|c|}
\hline & \multicolumn{2}{|c|}{ Anti-HMG1 } & \multicolumn{2}{|c|}{ Anti-HMG2 } \\
\hline & $\begin{array}{l}\text { Positive } \\
\text { (median } \\
\text { values) } \\
n=22\end{array}$ & $\begin{array}{l}\text { Negative } \\
n=6\end{array}$ & $\begin{array}{l}\text { Positive } \\
\text { (median } \\
\text { values) } \\
n=24\end{array}$ & $\begin{array}{l}\text { Negative } \\
n=4\end{array}$ \\
\hline AST (IU/l) & $\begin{array}{l}179 \\
\text { NS }\end{array}$ & 112 & $\begin{array}{l}131 \\
\text { NS }\end{array}$ & 319 \\
\hline ALT (IU/1) & $\begin{array}{l}144 \\
\text { NS }\end{array}$ & 160 & $\begin{array}{l}139 \\
\text { NS }\end{array}$ & 295 \\
\hline $\operatorname{IgG}(\mathrm{mg} / \mathrm{dl})$ & $\begin{array}{l}3234 \\
\text { NS }\end{array}$ & 2795 & $\begin{array}{l}3234 \\
\text { NS }\end{array}$ & 2288 \\
\hline $\operatorname{IgM}(\mathrm{mg} / \mathrm{dl})$ & $\begin{array}{l}297 \\
\mathrm{p}=0.025\end{array}$ & 435 & $\begin{array}{l}297 \\
\text { NS }\end{array}$ & 390 \\
\hline & $\begin{array}{l}\text { Anti-HM } \\
\text { (median } 2\end{array}$ & $\begin{array}{l}\text { I antibodies } \\
\text { zlues) }\end{array}$ & $\begin{array}{l}\text { Anti-HM } \\
\text { (median r }\end{array}$ & $\begin{array}{l}32 \text { antibodies } \\
\text { alues) }\end{array}$ \\
\hline Sex & & & & \\
\hline $\begin{array}{l}\text { Men }(n=6) \\
\text { Women }(n=22)\end{array}$ & $\begin{array}{l}14.2 \\
61.4\end{array}$ & $\mathrm{p}=0.029$ & $\begin{array}{l}17.5 \\
60.1\end{array}$ & $\mathrm{p}=0.012$ \\
\hline $\begin{array}{l}\text { Other immunologic } \\
\quad+(\mathrm{n}=7) \\
\quad-(\mathrm{n}=21)\end{array}$ & $\begin{array}{l}140.8 \\
83.5\end{array}$ & NS & $\begin{array}{l}111.4 \\
223.2\end{array}$ & NS \\
\hline $\begin{array}{l}\text { Liver cirrhosis } \\
\quad+(\mathrm{n}=3) \\
-(\mathrm{n}=25)\end{array}$ & $\begin{array}{l}28.2 \\
34.8\end{array}$ & NS & $\begin{array}{l}60.8 \\
43.3\end{array}$ & NS \\
\hline $\begin{array}{l}\text { Use of prednisolon } \\
\quad+(n=5) \\
-(n=23)\end{array}$ & $\begin{array}{l}\text { ampling } \\
31.9 \\
128.0\end{array}$ & NS & $\begin{array}{l}84.3 \\
240.0\end{array}$ & NS \\
\hline
\end{tabular}

p values by Mann-Whitney $U$ test.

AST, serum aspartate aminotransferase; ALT, serum alanine aminotransferase. clinical parameters selected were age, sex, serum aspartate aminotransferase, alanine aminotransferase, IgG, IgM, histology, treatment, clinical course, presence of liver cirrhosis and complications of any other immunological diseases. In $\mathrm{AIH}$, as shown in table 4, anti-HMG1 and anti-HMG2 antibody titres were significantly higher in women than in men. Patients with AIH with positive antiHMG1 antibody showed lower IgM. In eleven of the 12 patients with $\mathrm{AIH}$, who had high titres of anti-HMG1 or anti-HMG2 antibody before corticosteroid treatment (prednisolone, between 20 and $60 \mathrm{mg} /$ day), the antibody titre returned to normal or decreased after 5-10 months of treatment (data not shown). In PBC, however, no significant relation was observed between the presence of anti-HMG1 and/or anti-HMG2 antibodies and clinical status (data not shown).

\section{Discussion}

We found that antibodies to either HMG1 or HMG2 were detected more often in patients with $\mathrm{AIH}$ and PBC than in those with chronic hepatitis C and B. In AIH, the titres of antibodies to either HMG1 or HMG2 were significantly higher than in $\mathrm{PBC}$ and chronic hepatitis $C$ and $B$. Interestingly, the presence and titres of these antibodies in AIH correlated significantly with those of p-ANCAs. Preincubation of sera from patients with AIH with an excess mixture of HMG1 and HMG2 resulted in a decrease in the p-ANCA titre. These results strongly suggest that HMG1 and HMG2 are significant target antigens of p-ANCAs in AIH. However, p-ANCAs in AIH may recognise several candidate antigens other than HMG1 and HMG2. For example, cathepsin $\mathrm{G}$ and actin are reported to be antigens of ANCAs in AIH. ${ }^{14}{ }^{34}$ Indeed, anti-cathepsin G antibodies were detected more often here than in a previous study. ${ }^{34}$

ANA and SMA are useful seromarkers for AIH. In our study, the presence of anti-HMG1 and/or anti-HMG2 antibodies was independent of the presence of ANA and SMA. Interestingly, anti-HMG1 and/or anti-HMG2 antibodies disappeared or significantly decreased in titre after corticosteroid therapy in AIH. If the titres of anti-HMG1 and/or anti-HMG2 antibodies reflect disease activity, these antibodies can serve as useful clinical markers in $\mathrm{AIH}$, because the detection systems for these antibodies are simpler and more quantitative than those for ANA and SMA. The relations between the titre of anti-HMG1 and/or anti-HMG2 antibodies and the activity index of AIH are at present being analysed in a prospective follow up study.

In PBC, anti-HMG1 and/or anti-HMG2 antibodies were detected in both p-ANCA positive patients and p-ANCA negative patients, although these antibodies were hardly detected in p-ANCA negative patients with AIH. Moreover, some monoclonal anti-HMG1 and/or anti-HMG2 antibodies showed a p-ANCA staining pattern, whereas others did not (unpublished observation). These observations suggest that anti-HMG1 and/or anti- 
HMG2 antibodies can be divided into two subtypes by IIF using ethanol fixed neutrophils: a p-ANCA staining subtype and a negative staining one. Clarifying the epitopes of these antibodies would facilitate our understanding of the pathological difference between $\mathrm{AIH}$ and $\mathrm{PBC}$.

p-ANCAs are also commonly detected in PSC..$^{91012}$ In our preliminary study, p-ANCAs were detected in eight of 11 patients with PSC. Among p-ANCA positive patients, however, anti-HMG1 and/or anti-HMG2 antibodies were positive in only two patients (unpublished observation). It is unlikely that HMG1 and HMG2 are major p-ANCA antigens in PSC. It has been considered that the main autoimmune targets in AIH are hepatocytes, whereas those in PBC and PSC are intrahepatic bile capillary epithelia and bile duct epithelia respectively. Therefore the presence of anti-HMG1 and anti-HMG2 antibodies may reflect hepatocellular damage rather than bile duct epithelial damage.

The way in which HMG1 and HMG2 are involved in the pathogenesis of autoimmune liver disease is unknown. Besides its cytoplasmic and intranuclear localisation, HMG1 exists on the membrane of nerve cells and plays a role in enhancing neurite outgrowth..$^{35}$ It has also been reported that HMG1 is secreted by a murine erythroleukaemia cell line $\mathrm{e}^{37}$ Thus, if HMG1 exists on the surface of cells or in extracellular environments at inflammatory sites, the anti-HMG1 antibody may bind to HMG1, resulting in modification of the inflammatory process in autoimmune liver diseases. It therefore seems important to determine the distribution and expression of HMG1 and HMG2 molecules in liver cells to clarify the pathological role of anti-HMG1 and anti-HMG2 antibodies.

This work was supported in part by Grants-in-Aid from the Ministry of Education, Science, Sports and Culture of Japan, by research grants from the Ministry of Health and Welfare of Japan, and by grants from the Japan Rheumatism Association.

1 Lüdemann J, Utecht B, Gross WL. Anti-neutrophil cytoplasm antibodies in Wegener's granulomatosis recognize an elastinolytic enzyme. F Exp Med 1990;171:357-62.

2 Cohen Tervaert JW, van der Woude FJ, Fauci AS, et al. Association between active Wegener's granulomatosis and anticytoplasmic antibodies. Arch Intern Med 1989;149: 2461-5.

3 Nölle B, Specks U, Lüdemann J, et al. Anticytoplasmic autoantibodies: their immunodiagnostic value in Wegener's granulomatosis. Ann Intern Med 1989;111:28-40.

4 Falk RJ, Jennette JC. Anti-neutrophil cytoplasmic autoantibodies with specificity for myeloperoxidase in patients with systemic vasculitis and idiopathic necrotizing and crescentic glomerulonephritis. N Engl f Med 1988;318:1651-7.

5 Saxon A, Shanahan F, Landers C, et al. A distinct subset of antineutrophil cytoplasmic antibodies is associated with inflammatory bowel disease. f Allergy Clin Immunol inflammatory b

6 Duerr RH, Targan SR, Landers CJ, et al. Anti-neutrophil cytoplasmic antibodies in ulcerative colitis: comparison with other colitides/diarrheal illnesses. Gastroenterology 1991;100:1590-6.

7 Seibold F, Weber P, Klein R, et al. Clinical significance of antibodies against neutrophils in patients with inflammatory bowel disease and primary sclerosing cholangitis. Gut 1992;33:657-62.

8 Cambridge G, Rampton DS, Stevens TRJ, et al. Antineutrophil antibodies in inflammatory bowel disease: prevalence and diagnostic role. Gut 1992;33:668-74.

9 Klein R, Eisenburg J, Weber P, et al. Significance and specificity of antibodies to neutrophils detected by Western specificity of antibodies to neutrophils detected by Western
blotting for the serological diagnosis of primary sclerosing cholangitis. Hepatology 1991;14:1147-52.

10 Mulder AHL, Horst G, Haagsma EB, et al. Prevalence and characterization of neutrophil cytoplasmic antibodies in autoimmune liver diseases. Hepatology 1993;17:411-17.
11 Vidrich A, Lee J, James E, et al. Segregation of pANCA antigenic recognition by DNase treatment of neutrophils: ulcerative colitis, type 1 autoimmune hepatitis, and primary sclerosing cholangitis. F Clin Immunol 1995;15: 293-9.

12 Hardarson S, Labrecque DR, Mitros FA, et al. Antineutrophil cytoplasmic antibody in inflammatory bowel and hepatobiliary diseases: high prevalence in ulcerative colitis, primary sclerosing cholangitis, and autoimmune hepatitis. Clin Microbiol Immunol 1993;99:277-81.

13 Targan SR, Landers C, Vidrich A, et al. High-titre antineutrophil cytoplasmic anibodies in type-1 autoimmune hepatitis. Gastroenterology 1995;108:1159-66.

14 Orth T, Gerken G, Kellner R, et al. Actin is a target antigen of anti-neutrophil cytoplasmic antibodies (ANCA) in autoimmune hepatitis type-1. F Hepatol 1997;26:37-47.

15 Orth T, Keller R, Diekmann SO, et al. Identification and characterization of new ANCA antigens in patients with primary sclerosing cholangitis: catalase and alpha-enolase. Clin Exp Immunol 1998;112(suppl 1):45.

16 Sobajima J, Ozaki S, Okazaki T, et al. Anti-neutrophil cytoplasmic antibodies (ANCA) in ulcerative colitis: anticathepsin G and a novel antibody correlate with a refractory type. Clin Exp Immunol 1996;105:120-5.

17 Sobajima J, Ozaki S, Osakada F, et al. Novel autoantigens of perinuclear anti-neutrophil cytoplasmic antibodies (pANCA) in ulcerative colitis: non-histone chromosomal proteins, HMG1 and HMG2. Clin Exp Immunol 1997;107: 135-40.

18 Sobajima J, Ozaki S, Uesugi H, et al. Prevalence and characterization of p-ANCA directed against HMG1 and HMG2 in ulcerative colitis. Clin Exp Immunol 1998;111:402-7.

19 Uesugi H, Ozaki S, Sobajima J, et al. Prevalence and characterization of novel p-ANCA, antibodies to the high mobility group non-histone chromosomal proteins HMG1 and HMG2, in systemic rheumatic diseases. F Rheumatol 1998; 25:703-9.

20 Bustin M, Lehn DA, Landsman D. Structural features of the HMG chromosomal proteins and their genes. Biochim Biophys Acta 1990;1049:231-43.

21 Einck L, Bustin $M$. The intracellular distribution and function of the high mobility group chromosomal proteins. Exp Cell Res 1985;156:295-310.

22 Bustin M, Neihart NK. Antibodies against chromosomal HMG proteins stain the cytoplasm of mammalian cells. Cell 1979;16:181-9.

23 Uesugi H, Ozaki S, Sobajima J, et al. High mobility group non-histone chromosomal proteins HMG1 and HMG2: Are they p-ANCA target antigens? Clin Exp Immunol 1998; 112(suppl 1):52.

24 Majumdar A, Brown D, Kerby S, et al. Sequence of human HMG2 cDNA. Nucleic Acids Res 1991;19:6643.

25 Wen L, Huang JK, Johnson $\mathrm{BH}$, et al. A human placental cDNA clone that encodes nonhistone chromosomal protein HMG-1. Nucleic Acids Res 1989;17:1197-214.

26 Shirakawa H, Yoshida M. Structure of a gene coding for human HMG2 protein. $\mathcal{F}$ Biol Chem 1992;267:6641-5.

27 Shirakawa H, Tsuda K, Yoshida M. Primary structure of non-histone chromosomal protein HMG2 revealed by the nucleotide sequence. Biochemistry 1990;29:4419-23.

28 Halbwachs-Mecarelli L, Nusbaum P, Noël LH, et al. Antineutrophil cytoplasmic antibodies (ANCA) directed against cathepsin G in ulcerative colitis, Crohn's disease and primary sclerosing cholangitis. Clin Exp Immunol 1992;90:79-84.

29 Peen E, Almer S, Bodemar G, et al. Anti-lactoferrin antibodies and other types of ANCA in ulcerative colitis, primary sclerosing cholangitis, and Crohn's disease. Gut 1993;34:56-62.

30 Ohta Y. Report of the research subgroup of autoimmune hepatitis/primary biliary cirrhosis. Gastroenterol fpn 1993; 28(suppl 4):128-33.

31 Johnson PJ, Macfarlane IG. Meeting report: international autoimmune hepatitis group. Hepatology 1993;18:9981005.

32 Yoshida M, Shimura K. Unwinding of DNA by nonhistone chromosomal protein $\mathrm{HMG}(1+2)$ from pig thymus as determined with endonuclease. 7 Biochem (Tokyo) 1984;95: 117-24.

33 Wiik A. Delineation of a standard procedure for indirect immunofluorescence detection of ANCA. Acta Pathol Microbiol Immunol Scand 1989;97:12-13.

34 Lesavre P, Nusbaum P, Halbwachs-Mecarelli. Methods of detection of anticathepsin $\mathrm{G}$ autoantibodies in human. In: Gross WL, ed. ANCA-associated vasculitides: immunological and clinical aspects. New York: Plenum Press, 1993:257-61.

35 Merenmies J, Pihlaskari R, Laitinen J, et al. 30-kDa heparinbinding protein of brain (amphoterin) involved in neurite outgrowth: amino acid sequence and localization in the filopodia of the advancing plasma membrane. 7 Biol Chem 1991;266:16722-9.

36 Parkkinen J, Raulo E, Merenmies J, et al. Amphoterin, the 30-kDa protein in a family of HMG1-type polypeptides: enhanced expression in transformed cells, leading edge localization, and interactions with plasminogen activation. 7 Biol Chem 1993;268:19726-38.

37 Melloni E, Sparatore B, Patrone M, et al. Extracellular release of the 'differentiation enhancing factor', a HMG protein type, is an early step in murine erythroleukemia cell differentiation. FEBS Lett 1995;368:466-70. 